\title{
Methyl Donor Deficiency Affects Fetal Programming of Gastric Ghrelin Cell Organization and Function in the Rat
}

\author{
Carine Bossenmeyer-Pourié, ${ }^{*}$ Sébastien Blaise, * \\ Grégory Pourié, ${ }^{\dagger}$ Catherine Tomasetto, ${ }^{\ddagger}$ \\ Sandra Audonnet, ${ }^{*}$ Sandrine Ortiou, ${ }^{*}$ \\ Violette Koziel, ${ }^{*}$ Marie-Christine Rio, ${ }^{\ddagger}$ \\ Jean-Luc Daval, ${ }^{*}$ Jean-Louis Guéant, ${ }^{*}$ \\ and Bernard Beck* \\ From INSERM U954," Nutrition, Génétique et Expositions aux \\ Risques Environnementaux, Vandoeuvre; the Laboratoire de \\ Neurosciences, ${ }^{\dagger}$ and the Institut de Génétique et de Biologie \\ Moléculaire et Cellulaire, Illkirch, Université de Franche-Comté, \\ Besançon, France
}

Methyl donor deficiency (MDD) during pregnancy influences intrauterine development. Ghrelin is expressed in the stomach of fetuses and influences fetal growth, but MDD influence on gastric ghrelin is unknown. We examined the gastric ghrelin system in MDD-induced intrauterine growth retardation. By using specific markers and approaches (such as periodic acid-Schiff, bromodeoxyuridine, homocysteine, terminal deoxynucleotidyl transferase biotin-dUTP nick end labeling, immunostaining, reverse transcription-polymerase chain reaction), we studied the gastric oxyntic mucosa cellular organization and ghrelin gene expression in the mucosa in 20-day-old fetuses and weanling pups, and plasma ghrelin concentration in weanling rat pups of dams either normally fed or deprived of choline, folate, vitamin B6, and vitamin $B 12$ during gestation and suckling periods. MDD fetuses weighed less than controls; the weight deficit reached $57 \%$ at weaning $(P<0.001)$. Both at the end of gestation and at weaning, they presented with an aberrant gastric oxyntic mucosa formation with loss of cell polarity, anarchic cell migration, abnormal progenitor differentiation, apoptosis, and signs of surface layer erosion. Ghrelin cells were abnormally located in the pit region of oxyntic glands. At weaning, plasma ghrelin levels were decreased $(-28 \% ; P<0.001)$ despite unchanged mRNA expression in the stomach. This decrease was associated with lower body weight. Taken together, these data indicate that one mechanism through which MDD influences fetal programming is the remodeling of gastric cellular organization, leading to dysfunction of the ghrelin system and dramatic effects on growth. (Am J Pathol 2010, 176:270-277; DOI: 10.2353/ajpath.2010.090153)

Deficiency in folate and vitamin B12 has been well documented worldwide. It is present among the elderly as well as in some vegetarians and in men and women from developing countries as a result of poverty and inadequate intake. ${ }^{1-3}$ This deficiency leads to an increase in plasma homocysteine (Hcy), ${ }^{4}$ which is considered to be a risk factor for cardiovascular and neurodegenerative diseases. ${ }^{5}$ Vitamin B deficiency has a particularly severe impact during pregnancy as it is associated with early abortion, preeclampsia, neural tube defects, brain apoptosis, and intrauterine growth retardation. ${ }^{5-7}$ We have recently shown that methyl donor (folate, B12, and choline) deficiency (MDD) during gestation induces, in rat offspring, durable behavioral changes in adulthood despite a restored nutritional and metabolic status. Locomotor coordination is impaired in weaning deficient rats and deficits in exploratory behavior, spatial learning and memory persist. ${ }^{7}$ This is comparable with the cognitive impairments observed in aged subjects with diminished vitamin B12 and folate levels. ${ }^{8}$

Besides the brain, the stomach is also sensitive to this deficiency. Vitamin B12 deficiency is associated with different types of gastritis and atrophy. ${ }^{9-12}$ Pernicious anemia gastritis due to malabsorption of vitamin B12 is characterized by hypochlorhydria, dramatic changes in gastric oxyntic cells, and hormonal changes such as high basal gastrinemia. ${ }^{13-15}$

Accepted for publication September 4, 2009.

These data were presented in abstract form at the Seventh International Conference on Homocysteine Metabolism (Prague).

Supplemental material for this article can be found on http://ajp. amjpathol.org

Address reprint requests to Dr. Bernard Beck, INSERM U954, Faculté de Médecine BP 184, 54505 Vandoeuvre Cedex, France. E-mail: bernard.beck@nancy.inserm.fr. 
The stomach is also the main site for ghrelin synthesis. ${ }^{16,17}$ This hormone plays a significant role in growth through its dual role as a growth hormone-releasing factor and as an appetite stimulating peptide. ${ }^{16}$ Ghrelin mRNA is expressed in the rat fetus and placenta at early embryonic stages ${ }^{18}$ and ghrelin immunoreactive cells are detected in the rat stomach at embryonic day $18 .{ }^{19}$ An increased birth weight of pups or decreased fetal body weight observed, respectively, after ghrelin injection or immunization of dams against ghrelin support a role of ghrelin in late fetal development. ${ }^{19,20}$ More specifically, ghrelin is able to stimulate cell proliferation in the brain and skin as indicated by a dose-dependent increase of bromodeoxyuridine (BrdU) incorporation in cultured neurons and fetal skin cells. ${ }^{20-22}$ Both forms of circulating ghrelin (octanoylated and non-octanoylated) are important in this process. ${ }^{20}$ It may also have a specific role in neural tube closure. ${ }^{23}$ All together, these findings suggest that ghrelin might be associated with the clinical features of early vitamin B deficiency.

However, despite the high frequency of vitamin B deficiency during pregnancy, ${ }^{24}$ the influence of nutritional methyl donors during the gestational and pre-weaning periods of life has not been fully investigated. To the best of our knowledge, the gastric ghrelin system in MDDinduced intrauterine growth retardation has not been described. To address this, we performed an histochemical and biochemical analysis of the gastric mucosa organization and function using specific cellular markers in a MDD rat model ${ }^{7}$ of dams deprived of folate, vitamin B12, and choline from one month before mating until the weaning of their pups. Our results at the end of the gestation and at weaning demonstrate that the stomach is particularly sensitive to MDD already during the prenatal period and that ghrelin system in the offspring is particularly affected. They support the existence of a fetal programming of gastric cell organization and function, which affects growth in early life.

\section{Materials and Methods}

The study was conducted in accordance with the $\mathrm{Na}$ tional Institute of Health Guide for the Care and Use of Laboratory Animals.

\section{Protocol}

\section{Animal Treatments}

Adult female Wistar rats (Charles River, I'Arbresle, France; $n=37$ ) were maintained under standard laboratory conditions, on a 12 hours/12 hours light/dark cycle, with food and water available ad libitum. One month before mating, they were fed either standard chow diet $(n=18)$ (A03 diet, Scientific Animal Food and Engineering, Villemoisson-sur-Orge, France) or a diet lacking methyl donors, ie, vitamins B12, B2, folate, and choline $(n=19)$ (Special Diet Service, Saint-Gratien, France), according to Blaise et al..$^{25}$ Choline was eliminated from the diet because the alternative pathway for the methylation of Hcy to form methionine is catalyzed by betainehomocysteine methyltransferase that uses betaine, a me- tabolite of choline, as the methyl group donor. ${ }^{26}$ The assigned diets were provided to the dams ad libitum until weaning of the offspring (ie, postnatal day 21).

\section{Sample Collection}

At the end of the gestation, 20-day-old embryos (E20) were obtained from two MDD and two control dams. E20 fetuses were weighed and their stomachs were rapidly harvested and measured.

At weaning, rat pups randomly chosen in the different litters were sacrificed by excess halothane and weighed. Intracardiac blood samples were drawn from weanling control $(n=47)$ and MDD $(n=41)$ pups for the measurement of plasma concentrations of vitamin B12, B9, Hcy, total and active ghrelin and growth hormone. Their stomachs were then rapidly harvested and measured.

\section{Gastric Tissue Examination in E20 Fetuses and Weanling Pups}

\section{Light Microscopic and Immunohistochemical Analysis}

Pieces of stomach cut along their longitudinal axis were immediately frozen in methylbutane previously chilled to $-30^{\circ} \mathrm{C}$ and stored at $-80^{\circ} \mathrm{C}$. Analyses were performed on control $(n=9)$ and $\operatorname{MDD}(n=9)$ pups and fetuses ( $n=6$ for each group). Cryostat-generated sections, $20 \mu \mathrm{m}$, were stained with periodic acid-Schiff (PAS; Sigma-Aldrich, St. Quentin Fallavier, France) and counterstained with hematoxylin for general histology. Other sections were used for immunohistochemistry, and terminal deoxynucleotidyl transferase biotin-dUTP nick end labeling (TUNEL) assay.

Specific mouse anti-ghrelin antibody was used to localize ghrelin secreting cells. This monoclonal antibody recognizes both octanoylated and non-octanoylated forms of ghrelin but displays a higher affinity for the des-acyl form in competition studies. ${ }^{27}$ Mouse anti-intrinsic factor was used as a specific marker for zymogenic secreting cells (Novus Biologicals, Littleton, CO). The lineage-specific primary antibodies used were rabbit anti$\mathrm{H}^{+}-\mathrm{K}^{+} \alpha$ (Calbiochem, VWR International S.A.S, Fontenay sous Bois, France) specific for the $\alpha$ subunit of the $\mathrm{H}^{+}-\mathrm{K}^{+}$ATPase of parietal cells. Parietal cells were counted in 10 samples and expressed as cells per gland. Tetramethylrhodamine $B$ isothiocyanate-labeled Ulex europaeus type 1 agglutinin (UEA-1; Sigma-Aldrich) and fluorescein isothiocyanate-labeled Grifforia simplifolica II (GSII; Sigma-Aldrich) lectins were used as markers for mucus-secreting pit and neck cells, respectively.

Cell proliferation was evaluated by the labeling index using the incorporation of bromodeoxyuridine (BrdU). Pups were injected intraperitoneally with BrdU $(50 \mathrm{mg} / \mathrm{kg}$ body weight; Sigma-Aldrich) from day 9 to day 20. This method evaluates both cell proliferation and cell migration. Proliferating cells were labeled using a mouse antiBrdU antibody (Calbiochem, VWR International S.A.S). For quantification of specifically labeled cells, nuclei of total cells were stained with the fluorescent dye 4,6- 
diamidino-2-phenylindole $(0.5 \mu \mathrm{g} / \mathrm{ml}$ in phosphate-buffered saline; Sigma-Aldrich).

Apoptosis was investigated using the TUNEL method. TUNEL-positive cells were counted microscopically in control $(n=8)$ and MDD $(n=10)$ rats. Quantification of apoptotic cells was done using the Tdt-FragEL DNA fragmentation detection kit (Calbiochem, VWR International S.A.S) according to the manufacturer's instructions.

\section{Real-Time Quantitative Reverse Transcription-Polymerase Chain Reaction of Ghrelin Expression}

Total RNA was purified from nitrogen frozen stomach body section from control and MDD ( $n=5$ for each group) pups with the RNeasy lipid tissue kit following the recommendation of Qiagen (Courtaboeuf, France), which includes treatment with DNase. To check for possible DNA contamination of the RNA samples, reactions were also performed in the absence of Omniscript RT enzyme (Qiagen). Specific amplifications were performed using the following primers, forward: 5'-CCAAGAAGCCACCAGCTAAA-3', and reverse: 5'-CTGATTTCCAGCTCCTCCTC-3'. Expected product size was 103 bp. Quantitation was performed using ribosomal protein S29 (RPS29) as an internal standard with the following primers: forward, 5'-ATGGGTCACCAGCAGCTCTA-3' and reverse: 5'-CATGTTCAGCCCGTATTTGC-3'. Expected product size was $114 \mathrm{bp}$. Real-time polymerase chain reaction was performed using the DNA binding dye SYBR Green I for the detection of polymerase chain reaction products. Temperature cycling for the ghrelin run was 15 minutes at $95^{\circ} \mathrm{C}$ to activate the enzyme, followed by 50 cycles of $94^{\circ} \mathrm{C}$ for 10 seconds, $59^{\circ} \mathrm{C}$ for 15 seconds, and $72^{\circ} \mathrm{C}$ for 15 seconds. Temperature cycling for RPS29 run was 15 minutes at $95^{\circ} \mathrm{C}$ to activate the enzyme, followed by 50 cycles consisting of $94^{\circ} \mathrm{C}$ for 10 seconds, $55^{\circ} \mathrm{C}$ for 20 seconds, and $72^{\circ} \mathrm{C}$ for 15 seconds. Then melting curves analyses were performed by increasing temperature from 65 to $95^{\circ} \mathrm{C}$. Calculation of the results was done with the RelQuant software (Roche Diagnostics, Manheim, Germany). Results were expressed as arbitrary units by calculating the ratio of crossing points of amplification curves of ghrelin mRNA and internal standard.

\section{Plasma Assays}

Total ghrelin and acyl ghrelin were measured in duplicate by specific radioimmunoassays using commercial kits (RK-031-31; Phoenix Europe GmbH, Karlsruhe, Germany, for total ghrelin and GHRA-88HK, Labodia, Paris, France, for acyl ghrelin). Plasma samples from weanling pups were diluted threefold for total ghrelin assay and all samples were measured in the same assay. Plasma growth hormone levels were measured in duplicate with a radioimmunoassay kit (RGH-45HK; Linco Research, Inc., St. Charles, MO).

Plasma concentrations of vitamin B12 and folate were determined by radio-dilution isotope assay (simulTRACSNB, ICN, Costa Mesa, CA). Hcy concentrations were
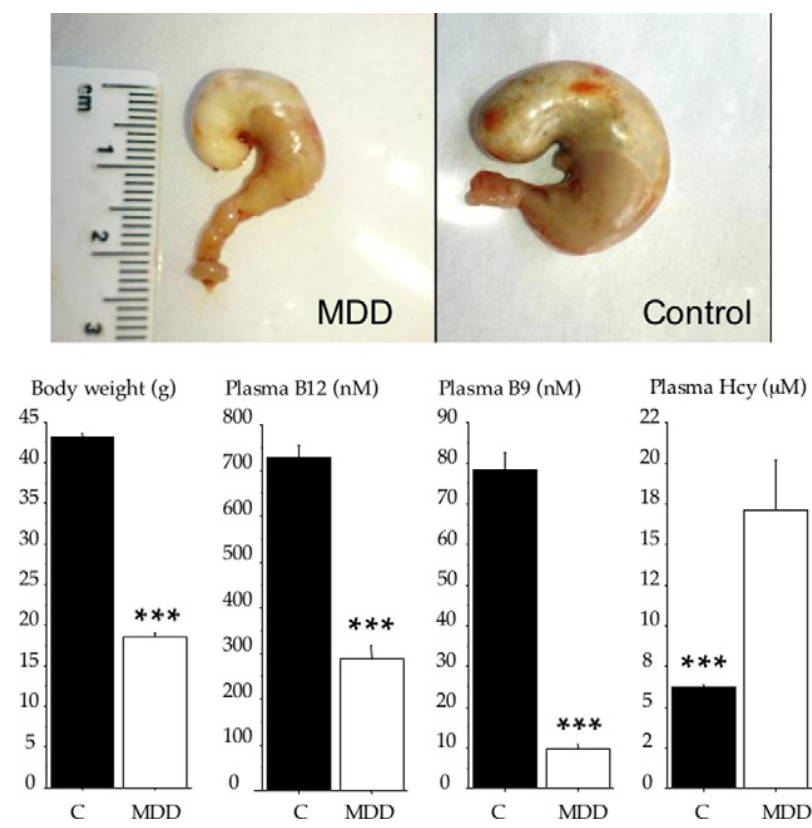

Figure 1. Photographs of stomach (upper panel) and body weight, plasma vitamin B12, B9, and Hcy variations (mean \pm SEM; lower panel) in control $(\mathrm{C})$ and MDD pups at weaning. ${ }^{* * * *} P<0.001$ between control and deficient rats.

measured by high performance liquid chromatography (Waters, St. Quentin, France) coupled to mass spectrometry (Api 4000 Qtrap Applied Biosystems, Courtabœuf, France). ${ }^{28}$

\section{Statistics}

Results are given as means \pm SEM. They were compared through Student's $t$-test or Wilcoxon test with Statview software (SAS Institute Inc., Cary, NC). A probability of less than 0.05 was considered statistically significant.

\section{Results}

All control dams $(n=18)$ had a successful gestation and kept their litter until the end of the suckling period. Among the MDD females $(n=19)$, three of them did not deliver and one of them killed all its pups on postnatal day 12 . There was no difference in litter size between control and MDD dams with a median of 11 pups per litter for both groups.

\section{MDD Effects on Body Weight, Plasma Vitamins $B$, Homocysteine, and Growth Hormone}

\section{Concentrations}

At the end of the gestation (E20), MDD fetuses $(n=23)$ weighed significantly less than control $(n=23)$ fetuses (3.47 $\pm 0.06 \mathrm{~g}$ versus $3.64 \pm 0.06 \mathrm{~g} ; P<0.04)$. At weaning (Figure 1$)$, MDD pups $(n=49)$ weighed $57 \%$ less than control $(n=47)$ pups $(P<0.001)$. Vitamin B9 and vitamin B12 were sixfold and approximately twofold lower, respectively, in deficient pups as compared with 
control pups ( $P<0.001$ for both vitamins). Homocysteine concentration was significantly higher in MDD pups than in control pups $(+174 \%$; $P<0.001)$. Plasma growth hormone levels were not significantly altered in MDD pups $(4.08 \pm 0.64 \mathrm{ng} / \mathrm{ml}$ versus $5.21 \pm 0.88 \mathrm{ng} / \mathrm{ml}$ (control); $P=0.33)$.

\section{MDD Effects on Gastric Structure and Function}

\section{MDD Modifies Stomach Size, Apoptosis, and Proliferation}

At the end of the gestation (E20), the stomach was smaller in MDD fetuses than in control fetuses $(0.83 \pm$ $0.02 \mathrm{~cm}$ versus $1.11 \pm 0.02 \mathrm{~cm} ; P<0.001$ ). Ratio of stomach size to body weight was $22 \%$ lower in MDD fetuses than in control fetuses $(P<0.001)$. Thickness of the gastric mucosa was also smaller in MDD fetuses than in control fetuses $(209.9 \pm 2.4 \mu \mathrm{m}$ versus $261.0 \pm 8.4$ $\mu \mathrm{m} ; P<0.0001)$. Thickness of mucus layer was significantly augmented in MDD fetuses (41.9 $\pm 0.8 \mu \mathrm{m}$ versus $36.3 \pm 1.6 \mu \mathrm{m}$ (control); $P=0.015$ ).

At weaning, the stomach size of MDD pups remained much smaller than that of control pups $(1.76 \pm 0.09 \mathrm{~cm}$ versus $3.02 \pm 0.05 \mathrm{~cm} ; P<0.001$; Figure 1, top panel). Ratio of stomach size to body weight was $16 \%$ lower in MDD pups than in control pups $(P<0.01)$.

Eosin-hematoxylin and PAS staining (Figure 2, A and B) showed by light microscopy irregular arrangement, reduction of the gastric gland layer, and increased thickness of the mucin surface layer in weanling MDD rats (Figure 2G). Gastric glands were enlarged and their density (number $/ \mathrm{mm}$ ) was significantly reduced by $20 \%(P<0.01)$.

TUNEL-positive apoptotic cells are shown in Figure 2, $\mathrm{C}$ and $\mathrm{D}$, for control and MDD rats respectively $(n \geq 6$ in each group). In control rats, the uppermost pit cells at the luminal surface, some neck cells (black arrowheads) and cells more frequently localized in the base region were TUNEL-positive. In MDD rats, TUNEL-positive apoptotic cells increased dramatically (sixfold; Figure $2 \mathrm{H}, P<0.01$ ) and were scattered throughout the oxyntic mucosa.

Evaluation of global cell proliferation, cell migration, and final localization after BrdU injection are shown in Figure 2, E and F, for control and MDD weanling rats, respectively. In control rats, BrdU-positive cells mostly migrated in the lower third of the gastric mucosa. Some newly proliferating cells (white arrows) were located in the isthmus region, which contains stem cells and progenitors responsible for the production of the different cell types. In MDD pups, BrdU-positive cells were mainly located from the neck to the pit region. The number of BrdU-positive cells was significantly higher (about twofold) in MDD pups, indicating a higher proliferation rate of the gastric oxyntic mucosa $(P<0.01$; Figure $2 \mathrm{H})$.

\section{MDD Modifies Cell Lineage in the Gastric Mucosa}

Labeling with UEA1 lectin specific for pit cell lineage showed distribution of pit cells along the luminal side of
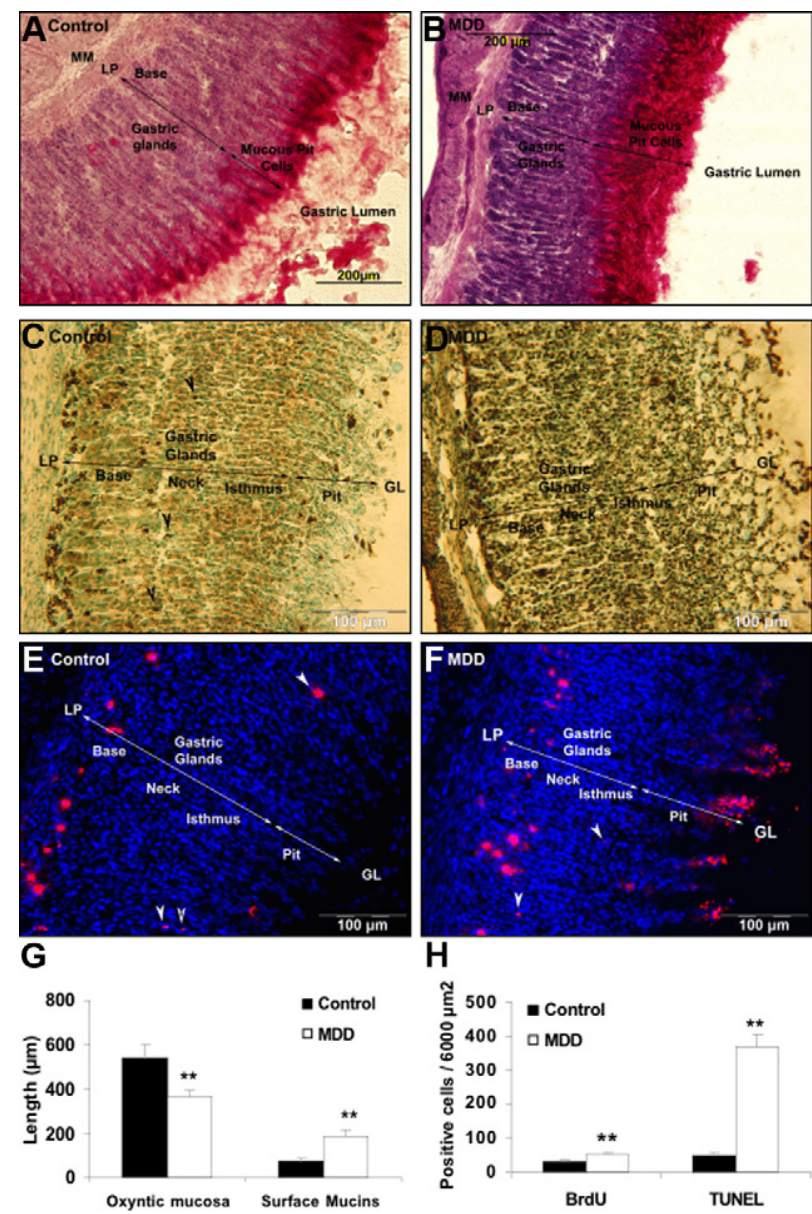

Figure 2. Immunohistological examination of the gastric oxyntic mucosa in control $(\mathbf{A}, \mathbf{C}, \mathbf{E})$ and MDD rats $(\mathbf{B}, \mathbf{D}, \mathbf{F})$ at weaning. Mucous cells labeling by PAS staining $(\mathbf{A}, \mathbf{B})$. Apoptosis detection by TUNEL assay: in control, pit cells, some neck cells (black arrowheads) and cells from the base region were TUNEL-positive (C), whereas in MDD apoptotic cells were found throughout the mucosa (D). BrdU labeling of proliferative cells: In control rats, newly proliferating cells were located in the isthmus region $(\mathbf{E}$, white arrowheads) and migrated to the base, whereas in MDD pups, BrdUpositive cells were mainly located from the neck to the pit region (F, white arrows); thickness of the total gastric oxyntic mucosa and of the surface mucin staining $(\mathbf{G})$; quantification of proliferative (BrdU positive) and apoptotic (TUNEL) cells in the gastric oxyntic mucosa (H). MM, muscularis mucosa; LP, lamina propria; GL, gastric lumen. ${ }^{* *} P<0.01$.

the epithelial unit of the oxyntic mucosa in control rats (Figure 3, A and C, red). In E20 MDD fetuses (Figure 3B), there was an expansion in the pit cell population occupying the upper middle of the mucosa. This situation was more pronounced at weaning (Figure 3D).

In the control fetuses and weanling rats, mucous neck cells labeled with GSII lectin were located in the neck and base regions of the oxyntic glands; none were found in the isthmus and pit region (Figure 3, A and B, green). In E20 fetuses (Figure 3B, green), these cells colonized the pit region. At 21 days of life, they disappeared from the base and were scattered from the neck to pit region (Figure 3D, green).

Parietal cells labeled with the antibody to the $\alpha$ subunit of the proton pump occupied the base of the gastric mucosa in control fetuses (Figure 3E) and were mainly scattered from base to low pit region at 21 days of life (Figure 3G). In MDD fetuses (Figure 3F), parietal cells 

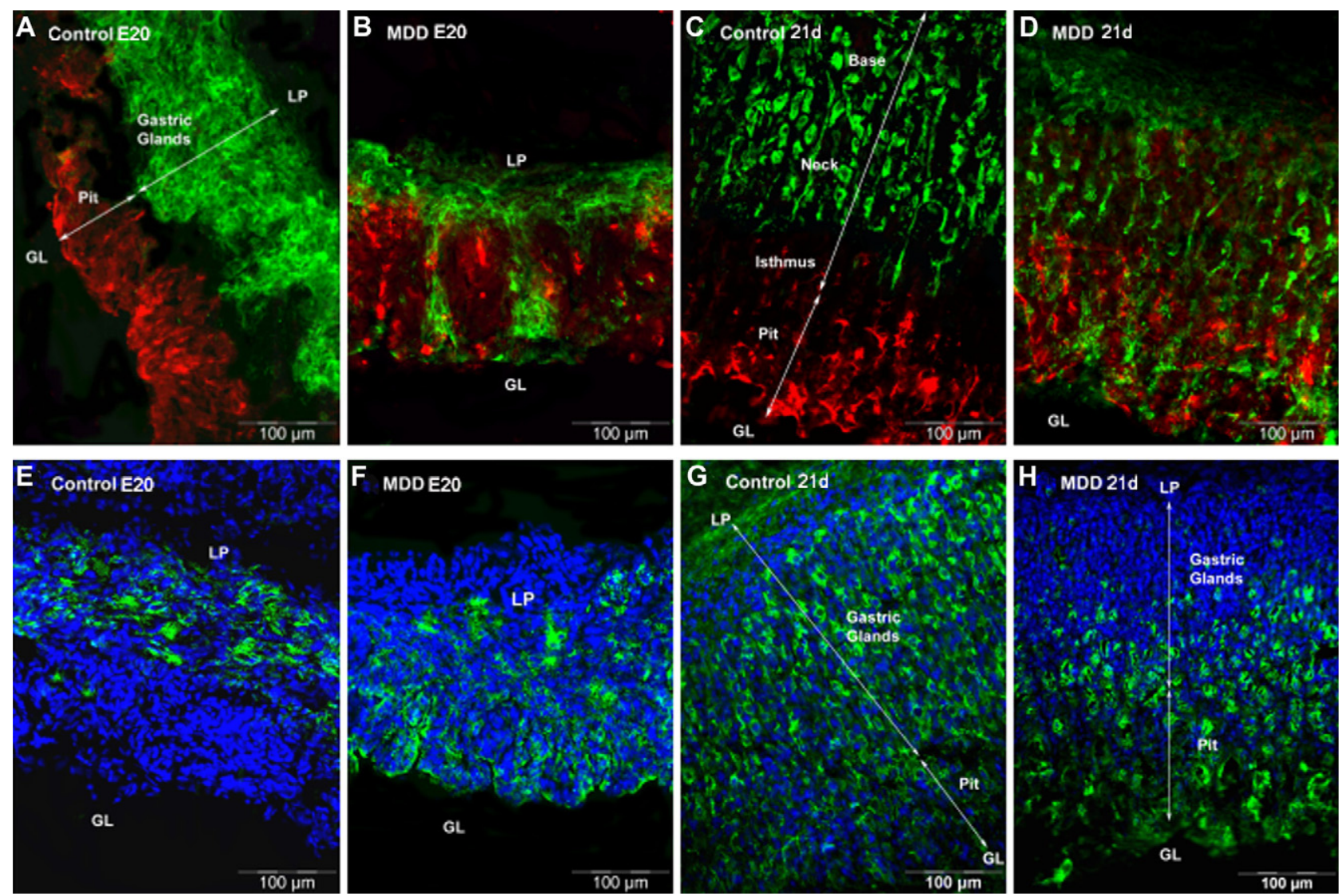

Figure 3. Immunohistological localization of specific cell type among the gastric glands in control and MDD E20 fetuses (four left panels) and rats at weaning (four right panels). A-D: Mucus-secreting pit cells labeled with UEA1 lectin are colored in red, whereas mucus-secreting neck cells labeled with GSII lectin are colored in green. $\mathbf{E}-\mathbf{H}$ : Parietal cells are colored in green. LP, lamina propria; GL, gastric lumen.

colonized the upper part of the mucosa. At 21 days of life, parietal cells were reduced in number, completely disappeared from the base and neck, and were mainly localized in the isthmus and pit region in MDD rats (Figure $3 \mathrm{H}$ ). At weaning, control rats had 12 parietal cells per gland whereas in MDD rats this number decreased to 7 $(P<0.01)$.

\section{MDD Alters the Secretory Cells and Function of the Stomach}

Ghrelin immunoreactive enteroendocrine cells were detected at the embryonic day 20 (Figure 4A, white arrowheads). In control E20 fetuses and 21-day-old pups, cells were distributed from the neck to the base region, but they were more abundant in the base of the gastric glands (Figure 4, A and C (white arrowheads), and 4E). In E20 MDD fetuses, the number of ghrelin-secreting cells were reduced in the base of the oxyntic glands (Figure $4 \mathrm{~B}$, white arrowheads) and increased in the pit region. At 21 days of life, this phenomenon was dramatically increased identifying a large part of surface pit cells as ghrelin-secreting cells with an aberrant localization (Figure 4, D and F).

Ghrelin mRNA expression in the stomach of weanlings and plasma ghrelin concentration are shown in Figure 5. Ghrelin mRNA expression in the stomach was not signif- icantly different between control and deficient pups. Plasma total ghrelin concentration was significantly lower in deficient pups than in control pups $(-28 \%$; $P<0.001)$. Acyl ghrelin contributed to 8 to $10 \%$ of total ghrelin, and this contribution was not significantly different between control and MDD rats $(P=0.41)$. Plasma total ghrelin was positively correlated with body weight $(r=$ 0.35; $P<0.001$ ).

The same localization pattern as ghrelin was found for the zymogenic cells producing the intrinsic factor (IF). These cells were situated in the base of the glands in control fetuses and rats (Figure 4, G and I) whereas they were localized predominantly in the pit region in MDD fetuses and rats (Figure 4, $\mathrm{H}$ and J).

\section{Discussion}

Our experiment was aimed at studying the effects of methyl donor deficiency (MDD) in rat dams on the gastric mucosa of their offspring at the end of the gestation and suckling periods, with a special focus on the structural and functional aspects of the pup's gastric wall. For this purpose, MDD began 1 month before mating and was maintained until the end of the suckling period. We focused our attention on the cellular and tissue distribution of gastric markers associated with mucosal differentiation 

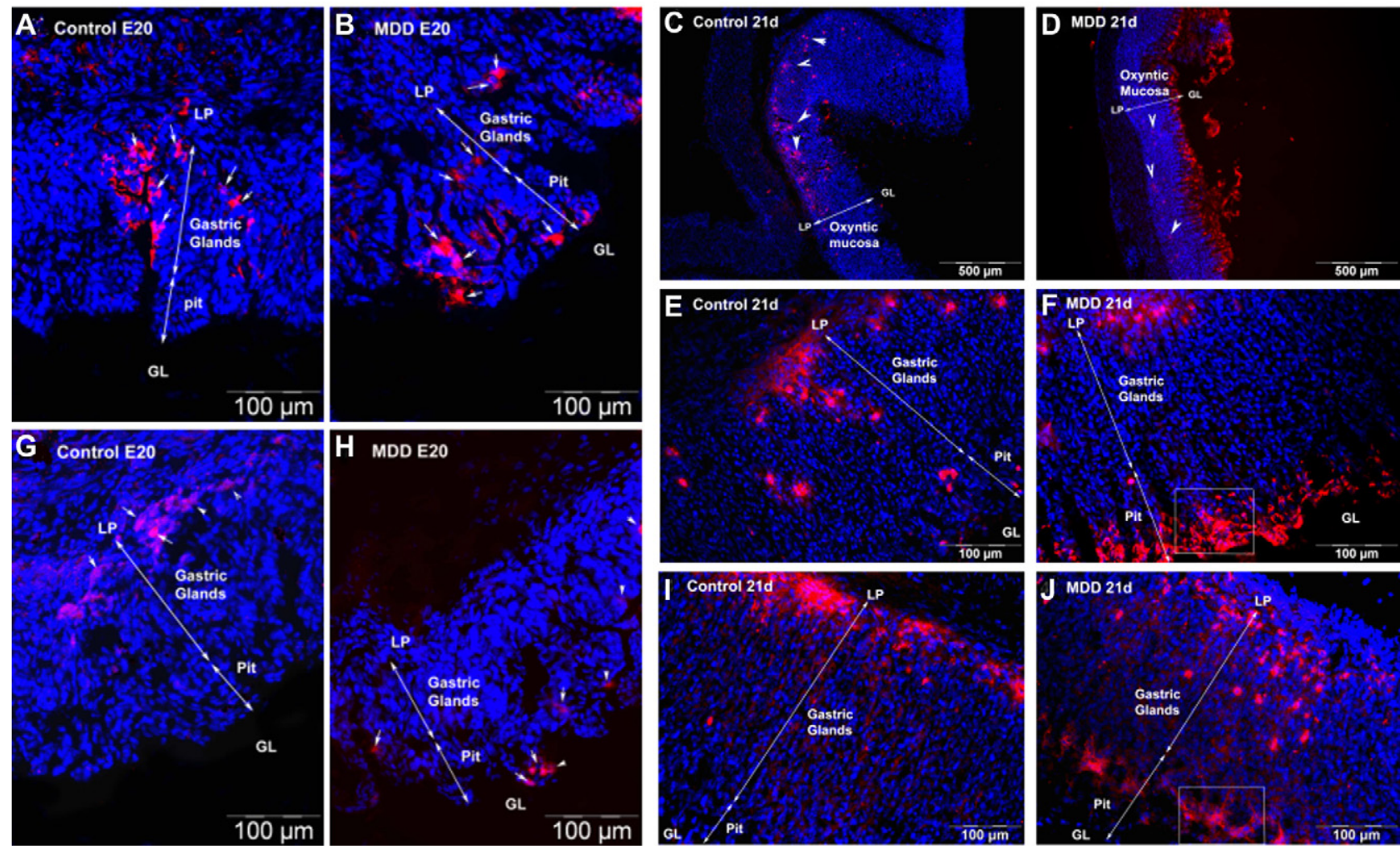

Figure 4. Localization of enteroendocrine ghrelin-producing cells colored in red (A-F, white arrows and arrowheads) and of zymogenic IF secretory cells ( $\mathbf{G}-\mathbf{J}$; red) in control and MDD E20 fetuses (four left panels) and rats at weaning (six right panels). An enlarged view of the areas in squares (F and $\mathbf{J}$ ) is shown in a supplementary figure (see Supplemental Figure S1 at http://ajp.amjpathol.org). LP, lamina propria; GL, gastric lumen.

and on the ghrelin system, an important endocrine system present in the stomach. ${ }^{16,29}$

First, we detected the classical effects of MDD described in the literature. ${ }^{4,30}$ Plasma vitamins B12 and B9 were markedly decreased, whereas homocysteine levels were clearly increased in MDD rats. These plasma variations were associated with a stunted pup growth until weaning. Growth retardation was already present at the end of the gestation and was further amplified during suckling as MDD weanling pups weighed less than half of the control pups. The stomach was markedly affected by

\section{Plasma ghrelin $(\mathrm{pg} / \mathrm{ml})$}

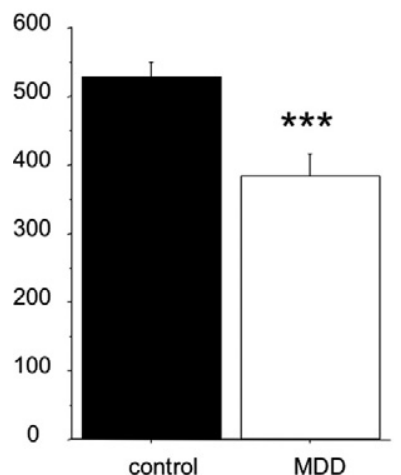

Gastric ghrelin expression (relative value)

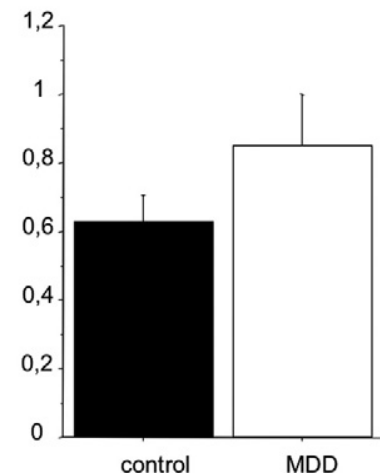

Figure 5. Plasma concentration of ghrelin (mean \pm SEM in $\mathrm{pg} / \mathrm{ml}$ ) and gastric ghrelin expression in control and MDD pups at weaning. ${ }^{* * * *} P<0.001$ between control and deficient rats.
MDD as illustrated by a very significant diminution in the stomach size and mucosa thickness in MDD fetuses and weanling pups. The lower ratio between stomach size and body weight in MDD rats at the end of gestation and weaning indicated that the decrease of stomach size occurred independently of body weight and supports that this organ was particularly sensitive to the deficiency. The existence of these anatomical changes already at E20 showed that the prenatal period is a critical period for the deleterious effects of MDD.

The integrity of gastric mucosa is normally maintained through the balance between apoptosis and cell proliferation. Excessive cell death over proliferation results in gastric ulceration or erosion such as atrophic gastritis and peptic ulcers. ${ }^{31}$ The whole extension of the glands normally occurs at postnatal days 18 to $22,{ }^{32}$ ie, at the time where we made our observations in weanling pups. In MDD rats, the proliferation rate as shown by BrdU staining increased about twofold whereas the apoptotic index (TUNEL) was increased about sixfold. This led to a reduced number of enlarged gastric glands and corresponded to a phenotype of atrophic gastritis. ${ }^{33}$ Twelveday-long BrdU incorporation showed positive cells mainly scattered in the lower third of the gastric mucosa in control pups and mostly located from the neck to the pit region in MDD pups. These results indicate changes in the location of progenitor cells that preferentially colonized the upper part of the gastric glands in response to increased tissue ulceration. Homocysteine levels were 
much higher in the gastric tissue of MDD rats than in control rats, in agreement with their increased homocysteine plasma concentration (data not shown). The adverse effects of either folic acid $^{34,35}$ or choline ${ }^{36}$ deficiency on the progenitor cell proliferation and apoptosis have been already observed in the fetal mouse brain. A similar phenomenon exists in the gastric mucosa of our MDD for the secreting cells. Normally, enteroendocrine cells, which rapidly renew themselves, move from the base of the gland, enter a death mechanism, and the dying cells are extruded into the lumen for their final elimination. ${ }^{37}$ This was well illustrated by the ghrelin cells in our experiment. In the control fetuses and rats, we found the X-type ghrelin-secreting cells localized from the neck to the base of the oxyntic glands with a few cells scattered at the top as commonly observed. ${ }^{19,38}$ In the MDD pups however, the increased apoptotic process speed up migration toward the pit, and dying ghrelinpositive cell accumulated near the lumen. When cell loss occurs in the hippocampus, it induces cognitive impairment, ${ }^{7}$ whereas when the stomach is concerned, it could contribute to organ and body growth retardation. The aberrant migration of progenitors that normally colonize the neck and base regions of the glands is supported by cell lineage analysis because it was also observed for the mucous neck cells and the IF cells. The IF cells are normally present in the base of the gland, ${ }^{39,40}$ but in MDD rats they were mainly localized in the pit region of the oxyntic mucosa.

Ghrelin cells and IF cells have opposite secretory patterns. Ghrelin is secreted in the blood. In MDD rats, the aberrant ghrelin cell localization in the pit region probably led to the one third reduction of the ghrelin plasma level. The active form of ghrelin (acyl ghrelin) was affected in the same manner as total ghrelin as indicated by similar proportion of this form in control and MDD pups. The ghrelin diminution was not associated with any change in total ghrelin mRNA level in the gastric mucosa. As plasma ghrelin normally augments in parallel with stomach ghrelin expression and content during the first three postnatal weeks, ${ }^{41,42}$ we assume that due to the accumulation of ghrelin cells at the pit of the gland, ghrelin in MDD rats might be falsely released and destroyed at the luminal side of the gastric mucosa and not secreted in the blood. Decreased ghrelin concentration could have a direct effect on the apoptotic phenomenon described earlier because when ghrelin is injected either intraperitoneally or directly in brain ventricles, it suppresses intestinal apoptosis. ${ }^{43}$ Ghrelin is also involved in rat growth through its stimulatory effect on growth hormone. ${ }^{16}$ There was a trend for lower circulating plasma growth hormones levels in MDD pups likely partly related to the lower ghrelin levels present in these pups. This might also contribute to their growth retardation.

Our results partly agree with those measured in men with chronic atrophic gastritis, which showed that the plasma ghrelin levels decrease with increasing extent of gastric mucosal atrophy. ${ }^{44-46}$ Yet, they differ on the origin of this decrease, as in chronic gastritis, ghrelin production by the stomach (mRNA expression and cell number) is decreased. ${ }^{45}$ In MDD rats, hypoghrelinemia is directly linked to a preferential secretion of the hormone in the gastric lumen in relation with the aberrant position of the ghrelin cells in the gastric mucosa. This improper positioning is likely related to MDD-induced errors during ontogenesis. Contrary to ghrelin, IF is secreted in the lumen of the stomach, and the abnormal localization of some IF-secreting cells in the pit region should not have any real deleterious consequences in MDD rats.

In summary, the stomach is an organ particularly sensitive to MDD during the early periods of life. MDD during gestation and lactation induced an increase of plasma and tissue homocysteine leading to aberrant gastric oxyntic mucosa formation at weaning. This phenomenon is due to atypical gland formation with loss of cell polarity, anarchic migration, and abnormal progenitor differentiation during the pups' development. The gastric ghrelin system (cellular organization and secretion) was particularly altered. This suggests that the in utero development period is of critical importance in terms of the availability of $\mathrm{B}$ vitamins and other methyl donors. Fetal programming of different regulatory systems of metabolic homeostasis is sensitive to macronutrient composition. ${ }^{47,48}$ Gross effects of vitamin B12/folate status during pregnancy on offspring insulin resistance, growth, or blood pressure have also been documented. ${ }^{49}$ Our results extend these observations on the critical role of micronutrients and indicate that MDD can profoundly affect fetal programming by remodeling gastric cellular organization leading to ghrelin dysfunction with dramatic effects on growth. Further epidemiological studies are needed to investigate whether methyl donors influence ghrelin release during human pregnancy and have subsequent effects on cognition, metabolic syndrome, and cardiovascular disease in adulthood.

\section{Acknowledgments}

We thank Dr. Elise Jeannesson and Mrs. Maryline Schwartz for their contribution in homocysteine assay.

\section{References}

1. Lindenbaum J, Rosenberg I, Wilson P, Stabler S, Allen R: Prevalence of cobalamin deficiency in the Framingham elderly population. Am J Clin Nutr 1994, 60:2-11

2. Herrmann W, Schorr H, Purschwitz K, Rassoul F, Richter V: Total homocysteine, vitamin $\mathrm{B}(12)$, and total antioxidant status in vegetarians. Clin Chem 2001, 47:1094-1101

3. Stabler S, Allen R: Vitamin B12 deficiency as a worldwide problem. Annu Rev Nutr 2004, 24:299-326

4. Finkelstein J: The metabolism of homocysteine: pathways and regulation. Eur J Pediatr 1998, 157:S40-S44

5. Mattson M, Shea T: Folate and homocysteine metabolism in neural plasticity and neurodegenerative disorders. Trends Neurosci 2003 , 26:137-146

6. Obeid R, Herrmann W: Homocysteine, folic acid and vitamin B-12 in relation to pre- and postnatal health aspects. Clin Chem Lab Med 2005, 43:1052-1057

7. Blaise SA, Nedelec E, Schroeder H, Alberto JM, BossenmeyerPourie C, Gueant JL, Daval JL: Gestational vitamin B deficiency leads to homocysteine-associated brain apoptosis and alters neurobehavioral development in rats. Am J Pathol 2007, 170:667-679

8. Riggs KM, Spiro A, Tucker K, Rush D: Relations of vitamin B-12, 
vitamin B-6, folate, and homocysteine to cognitive performance in the normative aging study. Am J Clin Nutr 1996, 63:306-314

9. Aimone-Gastin I, Pierson H, Jeandel C, Bronowicki J, Plénat F, Lambert D, Nabet-Belleville F, Guéant J: Prospective evaluation of protein bound vitamin B12 (cobalamin) malabsorption in the elderly using trout flesh labelled in vivo with 57Co-cobalamin. Gut 1997, 41:475-479

10. Krasinski S, Russell R, Samloff I, Jacob R, Dallal G, McGandy R, Hartz $\mathrm{S}$ : Fundic atrophic gastritis in an elderly population. Effect on hemoglobin and several serum nutritional indicators. J Am Geriatr Soc 1986, 34:800-806

11. Sipponen P, Laxen F, Huotari K, Harkonen M: Prevalence of low vitamin B12 and high homocysteine in serum in an elderly male population: association with atrophic gastritis and Helicobacter pylori infection. Scand J Gastroenterol 2003, 38:1209-1216

12. Dholakia K, Dharmarajan T, Yadav D, Oiseth S, Norkus E, Pitchumoni C: Vitamin B12 deficiency and gastric histopathology in older patients. World J Gastroenterol 2005, 11:7078-7083

13. Magnusson I, Cho J, Ihre T, Olsson J, Posloncek B, Uvnas-Moberg K, Ost A: Gastrin and somatostatin in plasma and gastric biopsy specimens in pernicious anemia. Scand J Gastroenterol 1985, 20:623-628

14. Mongin M, Harle J, Weiller P: The importance of hypergastrinemia in the diagnosis of Biermer's disease in the adult. Ann Gastroenterol Hepatol (Paris) 1993, 29:42-45

15. Testino G, Menardo G, Palombino M, Cornaggia M, De laco F, Molinari F: The gastric anatomico-functional aspects (parietal cell mass, stimulated acid secretion and gastrinemia) in pernicious anemia. Ann Ital Med Int 1993, 8:86-88

16. Kojima M, Kangawa K: Ghrelin: structure and function. Physiol Rev 2005, 85:495-522

17. Tomasetto C, Karam SM, Ribieras S, Masson R, Lefebvre O, Staub A, Alexander G, Chenard MP, Rio MC: Identification and characterization of a novel gastric peptide hormone: the motilin-related peptide. Gastroenterology 2000, 119:395-405

18. Torsello A, Scibona B, Leo G, Bresciani E, Avallone R, Bulgarelli L, Luoni M, Zoli M, Rindi G, Cocchi D, Locatelli V: Ontogeny and tissue-specific regulation of ghrelin mRNA expression suggest that ghrelin is primarily involved in the control of extraendocrine functions in the rat. Neuroendocrinology 2003, 77:91-99

19. Hayashida T, Nakahara K, Mondal MS, Date Y, Nakazato M, Kojima M, Kangawa K, Murakami N: Ghrelin in neonatal rats: distribution in stomach and its possible role. J Endocrinol 2002, 173:239-245

20. Nakahara K, Nakagawa M, Baba Y, Sato M, Toshinai K, Date $Y$, Nakazato M, Kojima M, Miyazato M, Kaiya H, Hosoda H, Kangawa K, Murakami N: Maternal ghrelin plays an important role in rat fetal development during pregnancy. Endocrinology 2006, 147:1333-1342

21. Zhang WZ, Hu YX, Lin TR, Fan YY, Mulholland MW: Stimulation of neurogenesis in rat nucleus of the solitary tract by ghrelin. Peptides 2005, 26:2280-2288

22. Johansson I, Destefanis S, Aberg N, Aberg M, Blomgren K, Zhu C, Ghè C, Granata R, Ghigo E, Muccioli G, Eriksson P, Isgaard J: Proliferative and protective effects of growth hormone secretagogues on adult rat hippocampal progenitor cells. Endocrinology 2008, 149:2191-2199

23. Yuzuriha $\mathrm{H}$, Inui $A$, Asakawa A, Ueno N, Kasuga M, Meguid MM, Miyazaki Jl, Ninomiya M, Herzog H, Fujimiya M: Gastrointestinal hormones (anorexigenic peptide YY and orexigenic ghrelin) influence neural tube development. FASEB J 2007, 21:2108-2112

24. Milman N, Byg K, Bergholt T, Eriksen L, Hvas A: Cobalamin status during normal pregnancy and postpartum: a longitudinal study comprising 406 Danish women. Eur J Haematol 2006, 76:521-525

25. Blaise S, Alberto J, Nédélec E, Ayav A, Pourié G, Bronowicki J, Guéant J, Daval J: Mild neonatal hypoxia exacerbates the effects of vitamin-deficient diet on homocysteine metabolism in rats. Pediatr Res 2005, 57:777-782

26. Selhub J: Homocysteine metabolism. Annu Rev Nutr 1999, 19:217-246

27. Heller R, Jenny M, Collombat P, Mansouri A, Tomasetto C, Madsen O, Mellitzer G, Gradwohl G, Serup P: Genetic determinants of pancreatic epsilon-cell development. Dev Biol 2005, 286:217-224

28. Ducros V, Belva-Besnet H, Casetta B, Favier A: A robust liquid chromatography tandem mass spectrometry method for total plasma homocysteine determination in clinical practice. Clin Chem Lab Med 2006, 44:987-990

29. Taub DD: Novel connections between the neuroendocrine and im- mune systems: the ghrelin immunoregulatory network. Vitam Horm 2008, 77:325-346

30. Maloney CA, Hay SM, Rees WD: Folate deficiency during pregnancy impacts on methyl metabolism without affecting global DNA methylation in the rat fetus. Br J Nutr 2007, 97:1090-1098

31. Moss S, Calam J, Agarwal B, Wang S, Holt P: Induction of gastric epithelial apoptosis by Helicobacter pylori. Gut 1996, 38:498-501

32. Alvares E, Gama P: Fasting enhances cell proliferation of gastric epithelium during the suckling period in rats. Braz J Med Biol R 1993, 26:869-873

33. Genta R: Helicobacter pylori, inflammation, mucosal damage, and apoptosis: pathogenesis and definition of gastric atrophy. Gastroenterology 1997, 113:S51-S55

34. Craciunescu CN, Brown EC, Mar MH, Albright CD, Nadeau MR, Zeisel SH: Folic acid deficiency during late gestation decreases progenitor cell proliferation and increases apoptosis in fetal mouse brain. J Nutr 2004, 134:162-166

35. Kruman II, Mouton PR, Emokpae R Jr., Cutler RG, Mattson MP: Folate deficiency inhibits proliferation of adult hippocampal progenitors. Neuroreport 2005, 16:1055-1059

36. Craciunescu CN, Albright CD, Mar MH, Song J, Zeisel SH: Choline availability during embryonic development alters progenitor cell mitosis in developing mouse hippocampus. J Nutr 2003, 133:3614-3618

37. Hall PA, Coates PJ, Ansari B, Hopwood D: Regulation of cell number in the mammalian gastrointestinal tract: the importance of apoptosis. J Cell Sci 1994, 107:3569-3577

38. Sakata I, Tanaka T, Matusbara M, Yamazaki M, Tani S, Hayashi Y, Kangawa K, Sakai T: Postnatal changes in ghrelin mRNA expression and in ghrelin-producing cells in the rat stomach. J Endocrinol 2002, 174:463-471

39. Shao J, Schepp W, Alpers D: Expression of intrinsic factor and pepsinogen in the rat stomach identifies a subset of parietal cells. Am J Physiol 1998, 274:G62-G70

40. Karam S, Straiton T, Hassan W, Leblond C: Defining epithelial cell progenitors in the human oxyntic mucosa. Stem Cells 2003, 21:322-336

41. Lee HM, Wang GY, Englander EW, Kojima M, Greeley GH: Ghrelin, a new gastrointestinal endocrine peptide that stimulates insulin secretion: enteric distribution, ontogeny, influence of endocrine, and dietary manipulations. Endocrinology 2002, 143:185-190

42. Nishi $Y$, Hiejima H, Mifune H, Sato T, Kangawa K, Kojima M: Developmental changes in the pattern of ghrelin's acyl modification and the levels of acyl-modified ghrelins in murine stomach. Endocrinology 2005, 146:2709-2715

43. Park JM, Kakimoto T, Kuroki T, Shiraishi R, Fujise T, Iwakiri R, Fujimoto K: Suppression of intestinal mucosal apoptosis by ghrelin in fasting rats. Exp Biol Med 2008, 233:48-56

44. Suzuki H, Masaoka T, Hosoda H, Nomura S, Ohara T, Kangawa K, Ishii $\mathrm{H}$, Hibi T: Plasma ghrelin concentration correlates with the levels of serum pepsinogen I and pepsinogen I/II ratio-a possible novel and non-invasive marker for gastric atrophy. Hepatogastroenterology 2004, 51:1249-1254

45. Osawa H, Nakazato M, Date $Y$, Kita H, Ohnishi H, Ueno H, Shiiya T, Satoh K, Ishino Y, Sugano K: Impaired production of gastric ghrelin in chronic gastritis associated with Helicobacter pylori. J Clin Endocrinol Metab 2005, 90:10-16

46. Isomoto H, Nakazato M, Ueno H, Date $Y$, Nishi Y, Mukae H, Mizuta $Y$, Ohtsuru A, Yamashita S, Kohno S: Low plasma ghrelin levels in patients with Helicobacter pylori - associated gastritis. Am J Med 2004, 117:429-432

47. Kozak R, Burlet A, Burlet C, Beck B: Dietary composition during fetal and neonatal life affects neuropeptide $Y$ functioning in adult offspring. Dev Brain Res 2000, 125:75-82

48. FernandezTwinn DS, Wayman A, Ekizoglou S, Martin MS, Hales CN, Ozanne SE: Maternal protein restriction leads to hyperinsulinemia and reduced insulin-signaling protein expression in 21-mo-old female rat offspring. Am J Physiol 2005, 288:R368-R373

49. Sinclair KD, Allegrucci C, Singh R, Gardner DS, Sebastian S, Bispham J, Thurston A, Huntley JF, Rees WD, Maloney CA, Lea RG, Craigon J, McEvoy TG, Young LE: DNA methylation, insulin resistance, and blood pressure in offspring determined by maternal periconceptional B vitamin and methionine status. Proc Natl Acad Sci USA 2007, 104:19351-19356 